\title{
SURFACE-FRACTURE-RELATED PHOTOLUMINESCENCE OF CdMnTe CRYSTALS
}

\section{R. Brazis a ${ }^{a}$ A. Selskis ${ }^{a}$, B. Kukliński ${ }^{\text {b }}$, and M. Grinberg ${ }^{b}$}

${ }^{a}$ Centre for Physical Sciences and Technology, A. Goštauto 11, LT-01108 Vilnius, Lithuania E-mail: brazi@@pfi.lt; aselskis@ktl.mii.lt

${ }^{b}$ Experimental Physics Institute of the University of Gdańsk, Wita Stwosza 57, 80-952 Gdańsk, Poland E-mail: fizmgr@univ.gda.pl

Received 29 August 2011; revised 28 February 2011; accepted 1 March 2011

Enhanced photoluminescence from sub-wavelength crystallites attached to the fractured surface of cleaved host crystals, and the transfer of emitted light to the dark side of macroscopically thick absorbing samples of $\mathrm{Cd}_{1 . x} \mathrm{Mn}_{x} \mathrm{Te}$ with $x=0.2$ is reported. The conventional model based on Kirchhoff's law of radiation is found to fail to describe the experimental photoluminescence line and its red shift relative to the optical absorption, and a more adequate novel theoretical model implying population inversion is proposed.

Keywords: CdMnTe, photoluminescence, optical absorption, electron microscopy, nanoparticles

PACS: $78.40 . \mathrm{Fy}, 78.20 . \mathrm{Ci}, 78.55 . \mathrm{Et}, 78.67 . \mathrm{Bf}$

\section{Introduction}

$\mathrm{Cd}_{1-x} \mathrm{Mn}_{x} \mathrm{Te}$ solid solutions have been primarily synthesised for experimental verification of the concept of exchange interaction of Mn magnetic moments with electron and hole spins [ [1-7]. The discovery of giant Faraday rotation in these crystals invoked magnetooptical device engineering [8-12]. It triggered research in low-dimensional structures with magnetic ions [13-15] for nanophotonics and spintronics [16]. Besides magnetic interaction, cadmium substitution just by smallersize $\mathrm{Mn}$ atoms brings about the crystal lattice contraction allowing for graded band-gap structure engineering for photoelectronic devices. Mn-related bands of high-energy photon absorption in $\mathrm{Cd}_{1-x} \mathrm{Mn}_{x} \mathrm{Te}$ also find applications in $\mathrm{X}$ - and $\gamma$-ray detectors [17].

One of the basic crystal parameters determining the spectral range of applications is the energy gap $E_{\mathrm{g}}$ between the valence band top and conduction band bottom. As the lattice constan decreases nearly linearly, $a / \mathrm{nm}=0.647-0.0133 x$
[18], $E_{\mathrm{g}}$ is nearly linearly increasing with the $\mathrm{Mn}$ molar contents $x$. Attempts to deduce $E_{\mathrm{g}}(x)$ from the optical absorption (OA) or photoluminescence (PL) spectral measurements indeed reveal nearly linear behaviour for $x<0.4$. Above this value, PL line branch appears at $2 \mathrm{eV}$, independent of $x$, which is related to transitions between the excited and ground states of $\mathrm{Mn}$ ions [5, 19-23]. OA measurements also show $E_{\mathrm{g}}(x)$ tending to saturate for $x>0.4$, but at somewhat higher level of $2.15-2.25 \mathrm{eV}$, depending on lattice temperature 12]. At any value of $x$, the values of $E(x)$ deduced from OA and PL turn out to be different, and the origin of this difference is not clear.

OA coefficient $\alpha(h v)$ measured as a function of photon energy $h v$ at the low-energy tail of the fundamental absorption edge is analysed conventionally using Urbach's rule and Varshni formula [24] and $E_{\mathrm{B}}$ is extracted as one of the five adjuste parameters depending on the $\mathrm{Mn}$ contents. Some of the adjustable parameters are formal, e. g. the "phonon energy", which needs to be about twice a high as the highest-energy phonon mode in thes materials: $\mathrm{LO}$ phonon energy is about $24 \mathrm{meV}$ in $\mathrm{CdTe}$, and it does not change much with the rise of Mn contents [25].

Energy gap determination seems to be more reliable when the exciton-related peak of the absorption coefficient is resolved [26]. Nevertheless, the "true" energy gap value remains questionable as the OA tail and OA peak measurements give different $E_{\mathrm{g}}$ values and the PL peak is red-shifted relative to that of $\mathrm{OA}$.

The shift of the PL peak has been explained recently by the inverted population of states in a matter spatially confined to the sub-wavelength scale [27-29]. The self-organised confinement of light emitters to nanometre-scale clusters in the $\mathrm{Cd}_{1-x} \mathrm{Mn}_{x} \mathrm{Te}$ bulk was deduced earlier from the analysis of composition disorder and magnetic fluctuations [30].

This article reports on experimental observation of new effects in light interaction with $\mathrm{Cd}_{1-x} \mathrm{Mn}_{x} \mathrm{Te}$ crystals: PL enhancement by subwavelength crystallites attached to the fractured surface of cleaved host crystals, and the transfer of emitted light to the dark side of macroscopically thick absorbing samples of $\mathrm{Cd}_{1-} \mathrm{Mn}_{x}$ Te with $x=0.2$. Theoretical PL line models and conclusions are presented below.

\section{Experiment}

$\mathrm{Cd}_{1-x} \mathrm{Mn} \mathrm{Te}$ crystals grown by the Bridgeman method with $x=0.2$ were selected in order to have band-gap PL below the Mn atomic-level luminescence line (being at $2 \mathrm{eV}$ ). Samples were prepared cence line (being at $2 \mathrm{eV}$ ). Samples were prepared
for PL measurements by cleaving in order to get opfor PL measurements by cleaving in order to get optically perfect surface area. However, at the cleaving instant, numerous different-size produced attaching to the surface by electrostatic and magnetic forces (Fig. 1).

The smallest resolvable crystallite size is about $10 \mathrm{~nm}$, and the largest crystallites observed are up to $1 \mu \mathrm{m}$ size. At this piloting stage of the experiment, we have omitted the specification of a particular crystallite responsible for emission. We observed bright light outbursts when scanning manually the samples by the Ar laser beam. Focusing the beam allowed to select visually a single star-like emitter and to record its spectrum (Fig. 2).

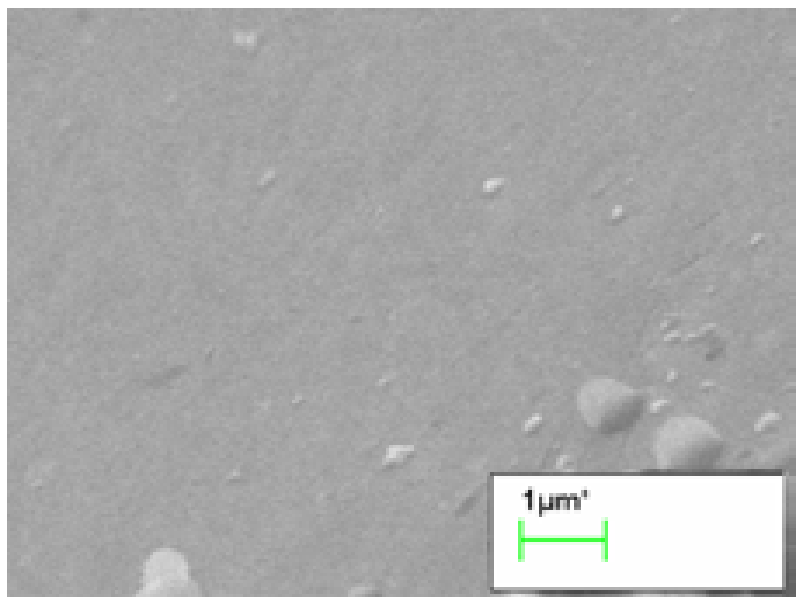

Fig. 1. View on the surface of cleaved $\mathrm{Cd} \mathrm{Mn}$ Te crysta $x=0$.2) by ZEISS scanning electron microscope EVO 50

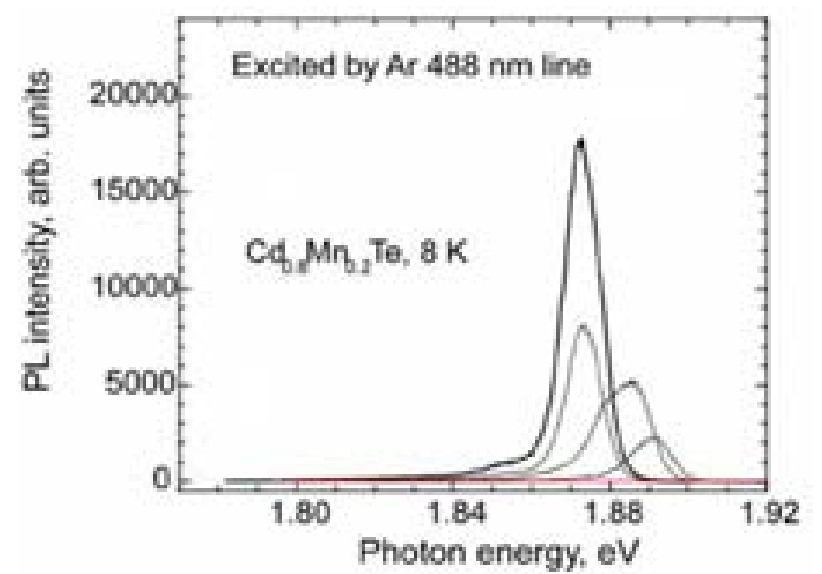

Fig. 2. $\mathrm{PL}$ of $\mathrm{Cd}_{1-x} \mathrm{Mn}_{x} \mathrm{Te}(x=0.2)$ excited by the $488 \mathrm{~nm}$ line of Ar laser at $T=8 \mathrm{~K}$ at different points on the surface. The line peaked at $1.89 \mathrm{eV}$ is recorded from the apparently crystallite-free area.

The crystallite PL peak positions are red-shifted relative to the peak of fundamental absorption (being at $1.91 \mathrm{eV}$ for this particular Mn mole fraction $x=0.2[31])$.

3. Theory

The modelling of PL spectral distribution is conventionally addressed to van Roosbroeck and Shockley who published their theory of recombination radiation balanced in details with the light absorption in crystals [32]. In this model, radiation intensity is 


$$
I(E)=D n^{3} \kappa \frac{E^{3}}{\exp \left[E /\left(k_{\mathrm{B}} T_{\text {ef }}\right)\right]-1}
$$
high compared to the crystal lattice temperature.

The choice of $T$, which enters the Planck's factor only, affects the intensity spectrum slope and magnitude, and the peak position is determined by the dispersion of the refraction and absorption coefficients. As is seen in Fig. 3, this theory does not model the experimental PL line shape the theoretical intensity maximum is practically at the position of maximum absorption, whereas the experimental PL peak is significantly redshifted.

Further we will turn to an alternative concep [27-29]. Suppose that the particles interacting with light can be in two allowed states only: the ground one with the energy $E_{l}$ and zero dipole moment and the excited one with the energy $E$ and a finite dipole moment. For the light energy absorption, dipole moment. For the light energy absorption,
the light-induced change of dipole moment need to be in phase with the light electric field, whereas the acts of energy emission need the dipole moment change to be in opposite phase to the ligh electric field. The Schrödinger equation solution results in the oscillator-like contributions to the dielectric function

$$
\begin{aligned}
& \varepsilon(E)=\varepsilon_{\infty}(E)+\frac{\beta_{l m}^{2} N_{1}}{\left[\left(E_{m}-E_{l}\right)^{2}-(E)^{2}\right]+\mathrm{i} E \Gamma_{l m}} \\
& -\frac{\beta_{m l}^{2} N_{m}}{\left[\left(E_{m}-E_{l}\right)^{2}-(E)^{2}\right]+\mathrm{i} E \Gamma_{m l}},
\end{aligned}
$$

where $\varepsilon_{\infty}(E)$ is the background dielectric func tion, $\Gamma_{l m}$ is the joint level broadening parameter, and $\beta_{l m}^{2}$ is the coefficient controlled by the square matrix element of the dipole moment operato for the $1-\mathrm{m}$ transition. The values of $\Gamma_{m l}$ and $\beta^{2}$ for $\mathrm{m}-\mathrm{l}$ transitions are here supposed to be the same as for $l-m$ transitions, and $N_{l}$ and $N_{m}$ are the occupation numbers of the ground and excited levels.

Let the light absorbing/emitting matter be bounded in a sub-wavelength-size spheroid surrounded by rounded approximation can be then used for finding the spheroid electric and magnetic moments [36]. The power absorbed or emitted by the spheroid electric dipole perturbation is [37]
$\mathrm{Cd}_{08} \mathrm{Mn}_{0.2} \mathrm{Te}$ excited by the $488 \mathrm{~nm}$ line $T=8 \mathrm{~K}$ (dots), and the blackbody rad for $T=400 \mathrm{~K}$ (dashed line).
Fig. 3. Light emission spectrum calculated by the for the refraction and absorption indexes $n(E)$ an $\kappa(E)$ of $\mathrm{Cd}_{0.8} \mathrm{Mn}_{0.2}$ Te determined from Ref. [31] (solid and the blackbody radiation spectrum

$$
\begin{aligned}
& P=\frac{1}{2} \frac{E}{\hbar} \varepsilon_{0} \varepsilon_{\mathrm{M}} V\left(\frac{1}{L}\right)^{2} \\
& \mathrm{x} \frac{\operatorname{Im} \varepsilon(E)}{\left[\operatorname{Re} \varepsilon(E)+\varepsilon_{\mathrm{M}} \gamma_{L}\right]^{2}+[\operatorname{Im} \varepsilon(E)]^{2}}\left|E_{0}\right|^{2} .
\end{aligned}
$$

Here $\varepsilon_{\mathrm{M}}$ is the dielectric constant of matrix surrounding the spheroid, $V$ is the spheroid volume, $L$ is its depolarisation factor (e. g. $L=1 / 3$ for the sphere), $\gamma_{L}=(1 / L)-1, E_{0}$ is the light wave electric field am$\gamma_{L}=(1 / L)-1, E_{0}$ is the light wave electric field am-
plitude in the matrix. The matrix dielectric constant plitude in the matrix. The matrix dielectric constant crystal interface. The crystallite depolarisation factor is generally tensor [ 38 and its values can be influenced by the crystallite image in the host crystal. A similar complexity of factors has been considered by Berreman in his theory [39] of infrared radiation scattering on the rough surface of ionic crystals. The pits and bumps at the surface in that model have been concluded to act as sub-wavelength spheroids with the fractional values of $\gamma_{L}$ giving rise to resonant distortions in the Reststrahl band.

By adapting these concepts for the visible light interaction with electronic oscillators, we compare here two simple cases of a spheroid being in air and that embedded in the host matrix. We take again the complex dielectric function $\varepsilon(E)$ of $\mathrm{Cd}_{0.8} \mathrm{Mn}_{0.2} \mathrm{Te}$ as deduced from reflectivity measurements in Ref [31] keeping the background component independent of whether the crystal is in normal or in pendent or in excited state and inverting sign (when modelling emission) of the component of inter-band transitions. This model gives the PL line shape and peak position in good agreement with the experiment (Fig. 4).

Although Fig. 4 presents calculations for the particular $(50 \mathrm{~nm})$ size spheroid, the peak position according to Eq. (3) should remain insensitive to the size change as far as the spheroid remains essentially smaller than the light wavelength. Some variation of the peak positions can arise depending on the crystallite shape due to shape-dependent depolarisation factors. The crystallite size, i. e. the mount of light-emitting matter, controls the peak height. The calculated PL spectra have smalle widths compared to the experimentally obtained spectrum, and this question remains for future analysis including both the homogeneous and in homogeneous broadening contributions.

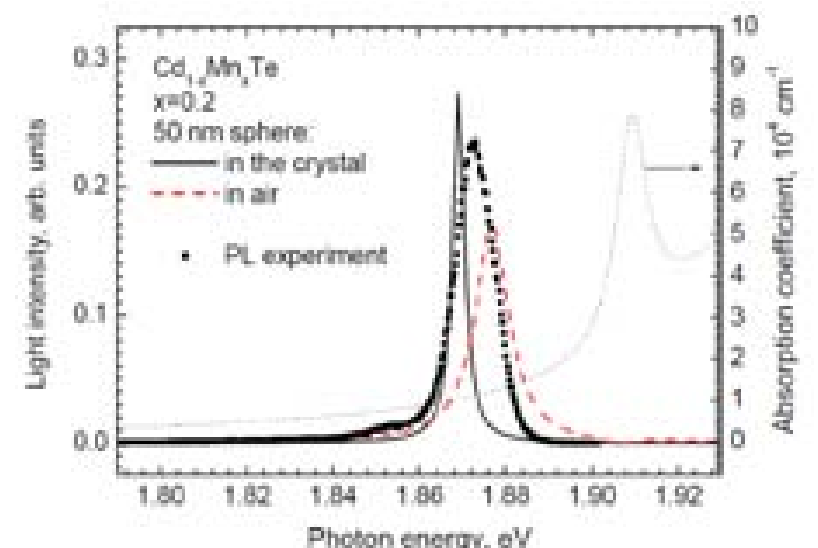

Fig. 4. Experimental PL intensity from a $\mathrm{Cd}_{0} \mathrm{Mn}_{02} \mathrm{Te}$ crystallite on the cleaved host crystal surface (squares) and light intensity calculated for the excited state of $\mathrm{Cd}_{0} \mathrm{Mn}$ Te sphere suspended in air (dashed line) an in the host crystal (solid line). The absorption coefficien for $\mathrm{Cd}_{\mathrm{Hn}} \mathrm{Te}$ from Ref [31] is included for comparifor $\mathrm{Cd}_{0.8} \mathrm{Mn}_{0.2} \mathrm{Te}$
son (dotted line).

As is seen in Eq. (3), for sufficiently small level broadening $\left.\Gamma_{l m} \rightarrow 0\right)$ and transparent matrix $\left(\varepsilon_{\mathrm{M}}>0\right)$, the power absorption/emission is peaked at the condition of $\operatorname{Re} \varepsilon(E)=-\varepsilon_{\mathrm{M}} \gamma_{L}$ that requires the value of $\operatorname{Re} \varepsilon(E)$ to be negative. For the normal population $\left(N_{l}>N_{m}\right)$ the resonance (peak absorption) takes place at the photon energy higher than the inter-level distance: $E_{\mathrm{OA}}>E_{m}-E_{l}$. For the inverse population, the resonance (peak emission) takes the place at a lower energy side: $E_{\mathrm{PL}}<E_{m}-E_{p}$ i. e. The PL peak is red-shifted relative to that of absorption. Taking for absorption the population numbers of $N_{1}=1, N=0$, and for emission the values of $N_{t}=0, N_{m}=1$, respectively, and tending $\Gamma_{l m} \rightarrow 0$, one gets from Eq. (2) the value of Re $\varepsilon(E)$ $=\varepsilon_{\infty} \pm \beta^{2} /\left[\left(E_{m}-E_{l}\right)^{2}-E^{2}\right]$ where $(+)$ stands for the process of OA, and (-) for PL. With the condition of $\operatorname{Re} \varepsilon(E)=\varepsilon_{\mathrm{M}} \gamma_{L}$ this gives

$E_{m}-E_{l}=\sqrt{\left(E_{\mathrm{OA}}^{2}+E_{\mathrm{PL}}^{2}\right) / 2}$,

and the red shift, which is-

$\Delta=E_{\mathrm{OA}}-E_{\mathrm{PL}}=\beta^{2} /\left[\left(\varepsilon_{\infty}+\varepsilon_{\mathrm{M}} \gamma_{L}\right) \sqrt{\left(E_{\mathrm{OA}}^{2}+E_{\mathrm{PL}}^{2}\right) / 2}\right] .(5)$

\section{.}


Although the band-gap $E_{g} \equiv E_{m}-E_{l}$ and the red photoluminescence observed on the dark side of shift $\Delta$ evaluation require complementary ex- $\mathrm{Cd}_{0 \mathrm{O}} \mathrm{Mn}$ Te crystals are encouraging features for periments on absorption in crystallites instead of experimental research continuation aiming at a absorption spectrum of the bulk crystal ${ }^{1}$, it is in- more controllable technology. The dark-side lightteresting to make at this stage tentative estima- ing relation to $\mathrm{Mn}^{2+}$ challenges for experimental retions based on Eqs. (4) and (5). Experimental OA search in the whole range of Mn molar contents. In and PL peak positions give the red shift, which is the more $\mathrm{Mn}$-reach structures, the theoretical mod$\Delta \approx 31 \mathrm{meV}$, and the oscillator strength measure el will also need to take into account internal optical for the conduction-valence-band transitions; it transitions in $\mathrm{Mn}^{2+}$ competing with the transition is $\beta^{2}=(0.88 \pm 0.34) \mathrm{eV}^{2}$, with the large error bar between the valence and conduction bands.

due to the uncertainty of $\varepsilon_{\mathrm{M}} \gamma_{L}$ values. The band-gap value for CdMnTe with Mn mole contents $x=0.2 \mathrm{i}$ then $E_{\mathrm{g}} \approx \sqrt{\left(E_{\mathrm{OA}}^{2}+E_{\mathrm{PL}}^{2}\right) / 2} \approx 1.89 \mathrm{eV}$.

\section{Dark side lighting}

Unexpected bright photoluminescence appeared also on the dark side of approximately $1-\mathrm{mm}$ - thick crystal. The absorption coefficient at the position of the PL peak is of the order of $1 \times 10^{4} \mathrm{~cm}^{-1}$ (Fig. 4) ruling out the conventional transmission of light from the illuminated one to the dark side. It is likely that energy transfer to the dark side is mediated by magnetically interacting $\mathrm{Mn}^{2+}$ ions

\section{Conclusion}

The scanning electron microscopy of the cleaved $\mathrm{Cd}_{0.8} \mathrm{Mn}_{0.2} \mathrm{Te}$ crystals revealed multiple crystallites created at the crystal cleaving instant. The crystallites are quite tightly bound to the surface by electrostatic and magnetic forces. The SEM-resolvable crystallite size ranged to $10 \mathrm{~nm}$. The scanning of the fractured surface with the Ar laser beam revealed the crystallites giving bright photoluminescence. The theory by van Roosbroeck and Shockley [32] based on Kirchhoff's law of radiation, which is conventionally used in the PL line analysis, does not describe the red shift of PL relative to OA. The red shift, which is the most common feature in experimental PL observations, is in reasonable agreemen with calculations based on the model suggested by Brazis [27-29] taking into account normal/inverted states of the sub-wavelength emitters/absorbers. The enhanced light emission and absorption by the fractured surface and particularly unexpected bright

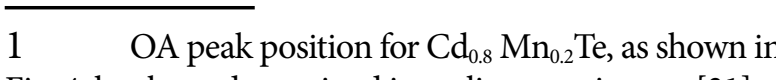
Fig. 4, has been determined in earlier experiments [31].

\section{Acknowledgments}

One of the authors (R. B.) acknowledges support by the EU COST Action MP0702 and the Research Counsil of Lithuanian (grant \#KEL-202/2011) for the research presentation at international conferences.

\section{References}

[1] N.T. Khoi and J.A. Gaj, Phys. Status Solidi B 83, K133 (1977).

2] A.V. Komarov, S.M. Ryabchenko, O.V. Terletskii, .I. Zheru, and R.D. Ivanchuk, J. Exp. Theor. Phys. 73,608 (1977) [in Russian].

3] J.A. Gaj, R.R. Gałązka, and M. Nawrocki, Solid State Commun. 25, 193 (1978).

(4) R.A. Abreu, J. Stankiewicz, and W. Giriat, Phys.

5] R.R. Gałazzka, S. Nagata, and P.H. Keesom, Phys.

.K. Furdyna, J. Appl. Phys. 53, 7637 (1982).

7] J.K. Furdyna J. Appl. Phys, 64, R29 (1988).

8] K. Morimoto, K. Takagi, and K. Matsubara, United , issued 12.06.1988.

] Y. Tomita, H. Oda, and M. Okuda, United States Patent 5245465, issued 09.14.1993.

[10]M. Yamanishi and H. Oda, Patent Document Number CA 2036759 C, issued 26.07.1994, Canadian Patent Database.

[11] V. Zayets, M.C. Debnath, and K. Ando, Appl. Phys. Lett. 84, 565 (2004).

12]Y. Hwang, S.-S. Chung, and Y. Um, Phys. Statu Solidi C 4, 4453 (2007).

[13]J.A. Gaj, in: Semiconductors and Semimetals, Vol. 25 (Academic Press Inc., New York, 1992) pp. 296-331.

[14]R. Brazis, R. Narkowicz, L. Safonova, and Nanostructures, eds. M.L. Sadowski, M. Potemski, Technol. 81, 315 (2000).

[15] W. Dobrowolski, J. Kossut, and T. Story, Handbook of Magnetic Materials, Vol. 15, ed. K.H.J. Bushow (Elsevie Science B.V., Amsterdam, 2006) pp. 298-378. T.Wojtowicz, in: Optical Properties ofSemiconductor and M. Grynberg, NATO Sci. Ser. 3 - High

[22] D. Leinen, Phys. Rev. B 55, 6975 (1997).

[24] Y. Hwang, Y. Um, and H. Kim, J. Korean Phys. Soc.
16] T. Dietl, Nat. Mater. 9, 965 (2010).

17] A. Hossain, Y. Cui, A.E. Bolotnikov, G.S. Camarda, G. Yang, D. Kochanowska, M Witkowska-Baran, A. Mycielski, and R.B. James, J. Electron. Mater. 38, 1593 (2009).

[18] A. Balzarotti, N. Motta, A. Kisiel, M. ZimnalStarnawska, M.T. Czyżyk, and M. Podgórny, Phys. Rev. B 31, 7526 (1985).

[19] M.P. Vecchi, W. Giriat, and L. Videla, Appl. Phys. Lett. 38, 99 (1981).

[20] M.M. Moriwaki, W.M. Becker, W. Gebhardt, and R.R. Galazka, Phys. Rev. B 26, 3165 (1982).

21]E.Müller and W.Gebhardt, Journal of Luminescence, 31-32, 479 (1984)

Laser Center of Bratislava, Slovak Republic, 26-28 Oct 2008) p. 22

[28]R. Brazis, in: 12th ICTON, 27 June-1 July 2010, Munich, Germany, Conf. Proc. (IEEE 2010 online) p. 4. [29]R. Brazis, in: 13th ICTON, 26-30 June 2011, Stockholm, Sweden, Conf. Proc. (IEEE 2011 online) p. 4.

[30]R. Brazis and J. Kossut, Solid State Commun. 122, $73(2002)$

L. Safonova, R. Brazis, and R. Narkowicz, Lith. J. Phys. 44, 421 (2004).

[32]W. van Roosbroeck and W. Shockley, Phys Rev. 94, 1558 (1954).

[23] Y. Hwan, Y. Um, and H. Park, J. Korean Phys. Soc. 58, $1312(2011)$ 34405 (1999)

[25]S. Venugopalan, A. Petrou, R.R. Gałązka, A.K. Ramdas, and S. Rodriguez, Phys. Rev. B 25, 2681 (1982).

[26]I. Caraman, G.I. Rusu, and L. Leontie, J Optoelectron Adv. Mater. 8, 107 (2006)

[27] R. Brazis, in: COST MP0702 Managing Committe (I) $b$-Wonctional Sub-Wavelength Photonic Structures" (International

B.I. Stepanov, Dokl. Akad. Nauk BSSR 112, 839 [i Russian, English translation in: Doklady Sov. Phys. 2, 81 (1957)].

[34] R. Kubo, J. Phys. Soc. Jpn. 12, 570 (1957).

[35]P.C. Martin and J. Schwinger, Phys. Rev. 115, 1342 (1959).

[36]R.S. Brazis and J.K. Furdyna, Phys. Rev. B 16, 3273

[37]R.S. Brazis, J.K. Furdyna, and J.K. Požela, Phys Status Solidi A 54, 11 (1979).

38]L.D. Landau, E.M. Lifshitz, Electrodynamics of Continuous Media (Moscow, 1959) pp. 42-43 [in

[39]D.W. Berreman, Phys. Rev. 163, 85 (1967).

\section{SKELTO PAVIRŠIAUS SĄLYGOTA CdMnTe KRISTALŲ FOTOLIUMINESCENCIJA}

R. Brazis ${ }^{a}$, A. Selskis ${ }^{\text {a }}$ B. Kukliński ${ }^{\text {b }}$ M. Grinberg ${ }^{\mathrm{b}}$

${ }^{a}$ Fiziniu ir technologijos moksly centras, Vilnius, Lietuva

Gdansko universiteto Eksperimentines fizikos institutas, Gdanskas, Lenkija

Santrauk

Eksperimentiškai tiriant skelto $\mathrm{Cd}_{1-x} \mathrm{Mn}_{x} \mathrm{Te}(x=0,2)$ monokristalo paviršiaus fotoliuminescenciia nustatyta kad švytèjimas sustiprèja kiekvieną kartą, kai žadinantis Ar lazerio spindulys nutaikomas $\mathfrak{i}$ kuri nors iš aibès kristalitŭ, kuriais paviršius pasidengia skaldymo metu. Ryškus švytejimas aptiktas ir tamsiojoje (nesužadintoje) pusèje, šviesai praejus per storą neskaidru kristala.

Elektroniniu mikroskopu paviršiuje buvo pastebèti kristalitai didesni už dešimtị nanometru. Parodyta, kad iprastinis fotoliuminescencijos modelis, pagristas Kirchhoff o spinduliavimo dessniu, neaprašo eksperimentinio spektro smailes raudonojo poslinkio nuo su位 dviejų lygmenų normalios ir apgrązos už pildos teorija. 